\title{
Research on the Application of Internet Information Technology in Higher Mathematics Classroom Teaching
}

\author{
Wang Yan \\ Nanchang Institute of Science and Technology, Nanchang, China
}

Keywords: Internet information technology; higher mathematics; classroom teaching; application

\begin{abstract}
With the progress of science and technology, Internet information technology has been widely applied in various field. Especially, in the development of education, the application of this technology plays an important role. Under the influence of Internet information technology, traditional teaching mode changes a lot, which promotes the reform of higher mathematics classroom teaching to a certain extent. More and more teachers begin to conduct deepening reform on teaching system by the aid of Internet information technology, realizing the purpose of optimizing the channels of knowledge propagation and strengthening the efficiency of knowledge transfer. At the same time, the quality and efficiency of higher mathematics teaching improves greatly. Therefore, this paper discusses the application of Internet information technology in higher mathematics classroom teaching, starting from task-driven method, and describes the specific application of this technology.

In higher institutions, higher mathematics is an important part of the basic quality training course and one of effective methods for students to realize advanced studies and innovation. However, in traditional higher mathematics teaching, students are in passive listening throughout most of the time, with single channels to obtain knowledge, thus it is difficult to realize individualized education goal. Whereas, higher mathematics is higher logic and abstract, with the constraints of time and space, in traditional classroom teaching, it is impossible to transfer abstract knowledge into visualized information which can be easily understood, and it is difficult to transform logic thinking to students' capacity of analyzing and solving problems, and to closely combine higher mathematics with related practical application activities, which results in that students' learning interest and innovative thinking cannot be effectively mobilized. Therefore, how to apply Internet information technology to reform traditional teaching and improve the effect of higher mathematics classroom teaching is the project to be studied by relative colleges and universities.
\end{abstract}

\section{Task-driven Method}

The application of Internet information technology in higher mathematics shall be implemented comprehensively and orderly with solidly theoretical basis and advanced guiding thought. Starting from task-driven method, this paper effectively integrates higher mathematics teaching with Internet information technology. Task-driven method is a student-centered teaching method driven by task. Specifically, it takes constructivism teaching theory as the basis, combines students' learning with relative task, and effectively inspires students' subjective initiative so that students can realize the teaching goal in accomplishing tasks, and teachers are required to offer guidance and encouragement in this process. [1]

In the application of task-driven method, teachers shall divide teaching contents more detailedly to multiple tasks, arrange students and perform tasks according to curriculum arrangement. To be more specific, it is to distribute tasks before class, organize students to analyze in class and finish task exploration after class. Whereas, in the whole teaching process, the application of Internet information technology shall be strengthened. By task-driven method, students can actively learn knowledge points in higher mathematics and effectively integrate pieced learning contents, so as to more comprehensively grasp higher mathematics knowledge. In actual teaching, teachers shall consider tasks as the driving force and students as the subject, and strengthen the application of 
Internet information technology through self-guidance, so as to realize the effective innovation in classroom teaching method of higher mathematics. [2]

\section{The Specific Application of Internet Information Technology in Higher Mathematics Classroom Teaching}

The classroom teaching of higher mathematics, taking Internet information technology as teaching tool, involves many contents, shown in detail.

\subsection{The application in teaching preparation}

Before the teaching, teachers are required to conduct a comprehensive analysis according to social professional requirement and students' professional characteristics, and stress the hierarchical teaching. Based on actual situations of students, the design of tasks can be targeted, making the realization of individualized training goal possible. However, many preparation shall be done well for the effective application of Internet information technology.

\subsubsection{Preparation of hardware}

The classroom teaching of higher mathematics requires corresponding hardware as basic guarantee, including computer, mobile terminal, campus wireless network, multi-media and so on. The development of modern science and technology drives the construction of colleges and universities to become more and more modern, and personal mobile terminal has been effectively popularized, which lays a foundation for the scientific application of Internet information technology. In teaching, teachers shall make full use of these resources to realize relative teaching goals. [3]

\subsubsection{Preparation of software}

The design contents of software is rich, including communication software, mathematics tool software, CAI courseware and so on. In the preparation of CAI courseware, teachers shall devote much energy, launching task book before class, and providing introduction and notes about tasks and multi-media courseware of knowledge points for tasks. Besides, mathematics tool software can promote the accomplishment of tasks for students, such as matrix software Matlab, numerical calculation software Lingo, statistical software Origin and symbolic operation software Mathematica and so on. In general, students know less about these software, so it is necessary for teachers to provide effective guidance. As for software, communication software is also important, because it is the basic guarantee for communication and interaction between teachers and students and between students. At the same time, the effective application of communication software exactly breaks through the constraints of time and space in teaching activities, so that students can learn anywhere at any time, clearing the learning goal. Teachers can have real-time understanding of students' learning and accomplishment of tasks, so that they can adjust timely the teaching contents according to students' need in teaching, resulting in more targeted and effective teaching activities. At present, commonly-used social media like QQ and WeChat can be applied to build up network platform to realize the purpose of online teaching. [4]

\subsubsection{Preparation of resource base}

There are rich information resources in Internet. However, it should be noted that, the more information resources acquired, the better the teaching effect is not true. Because information is flooded, there will inevitably be the problem of unevenness. In order to prevent students from blindly learning and waste learning time, teachers should provide students with an efficient resource base to lay a foundation for students' self-learning, and the content should be closely related to the teaching content, such as MOOC resource, mini-games or video inspiring students' interest, question bank for testing learning results and etc. Besides, teachers cannot build up resource base once for all, and they need to optimize those bases continuously. The updating of Internet information is rapid, so it is necessary to update contents of resource bases timely so that students 
can obtain optimal learning resources. [5]

\subsection{The actual application in teaching}

In the teaching of higher mathematics, the assignment of tasks cannot be hasty. It is necessary to provide students with a process to adapt to it and be familiar with it. Starting from task-driven method, teaching activities are implemented through Internet, and specific operation is described in detail.

\subsubsection{Task assignment}

The assignment of the task, shall adhere to the principle of from the shallower to the deeper, and gradually improve students' task completion ability. For the initial task, some simpler contents can be arranged, for example, to collect mathematics history and related characters in Internet during the spare time, understand the background knowledge of higher mathematics, and fully understand the knowledge thread of higher mathematics, also play mathematics mini-games, such as Blasting Higher Mathematics, and talk about mathematics knowledge implied in the game. The main purpose of setting up the initial task is to fully stimulate students' interest in higher mathematics, so that they can re-recognize higher mathematics and improve the interest of higher mathematics teaching. In the deepening of task, the difficulty can be appropriately increased. For instance, MOOC can be applied to help students learn related knowledge points, shown in Figure 1, and accomplish the preview and exercises of follow-up course, so as to reach the teaching effect of flipped classroom and effectively train students' independent learning ability. In fact, the teaching task itself is to enhance students' ability of analyzing and solving problems, so as to promote the development of students' innovative ability and thinking ability. In addition, tasks can realize the effective application of higher mathematics in other disciplines, such as the analysis of stock curve with the use of function and extreme value, the analysis of bank interest rate by infinitus, the analysis of water flow rate in pipe by calculus and so on. [6]

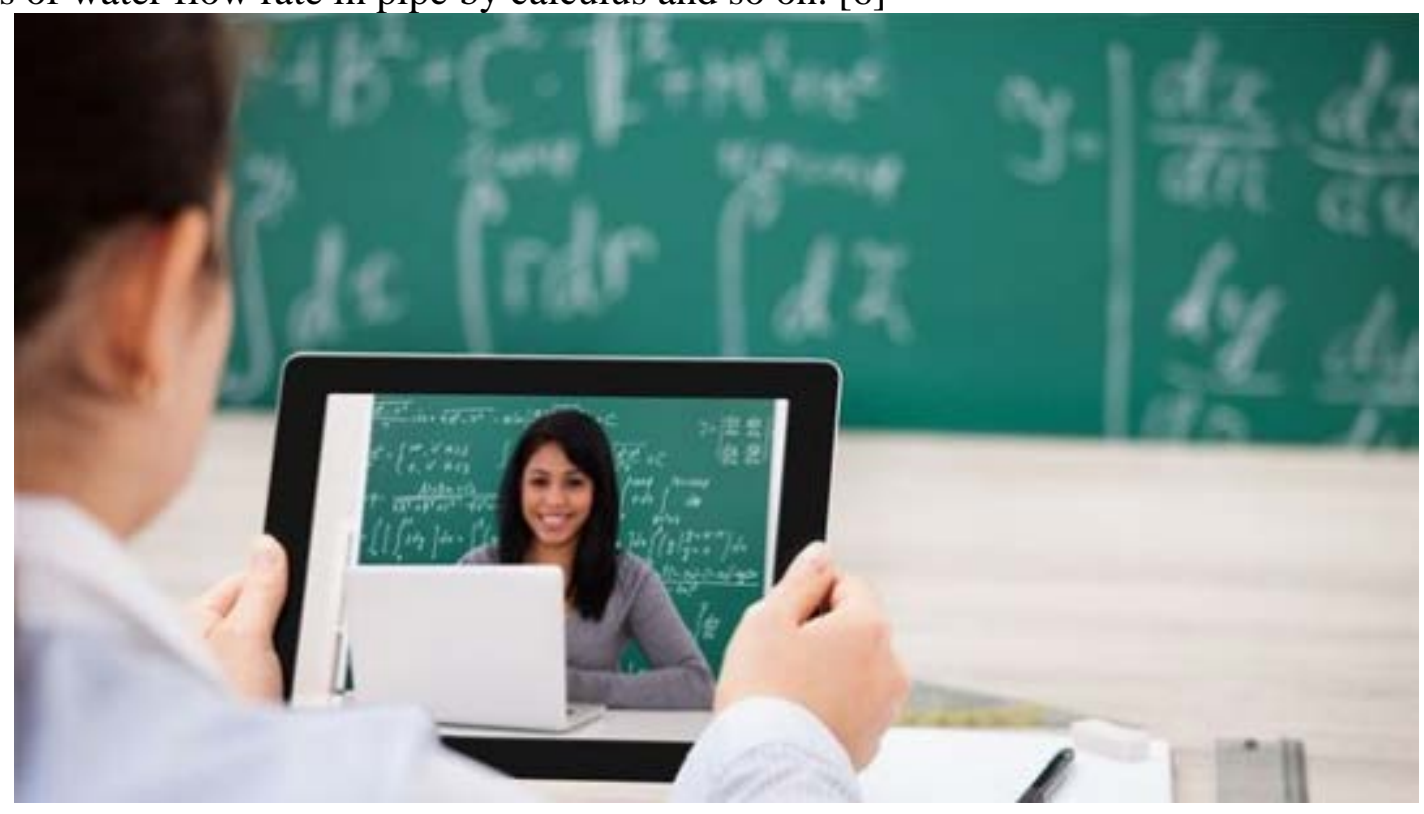

Figure 1

\subsubsection{Task analysis}

In the classroom, teachers should strengthen the analysis and explanation of relevant knowledge points of the task, make full use of multimedia courseware, and present abstract and complex knowledge points intuitively. For example, the meaning of a derivative or the nature of a function can be demonstrated by geometer sketchpad. Teachers should provide notes about the task, divide the complex tasks, and fully mobilize students' enthusiasm. Teachers should create classroom atmosphere in the teaching, and improve the ease, pleasure and fun of classroom teaching. Of course, the task analysis cannot be limited to the classroom. It is necessary to strengthen the 
application of network platform, and timely answer relevant questions to ensure the successful completion of the task. [7]

\subsubsection{Task accomplishment}

In terms of task accomplishment, single-person task and group task should be set up at the same time. During the task execution, if students cannot have a thorough understanding of certain knowledge points, in addition to encouraging students' exploration, they also need to guide students to use MOOC and use Internet resources to find relevant information, advocate teamwork, actively organize students to communicate and discuss online and offline, and after completing the task, conduct a comprehensive summary, and give evaluation and feedback. In this way, students' knowledge can be gradually internalized, thus promoting the development of students' quality. Teachers can present the cases of good task results, guide students' task activities with those as typical examples, and provide evaluation and correction, so that students can communicate effectively with each other and obtain a broader thinking space and break the limit of personal thinking, shown in Figure 2. [8]

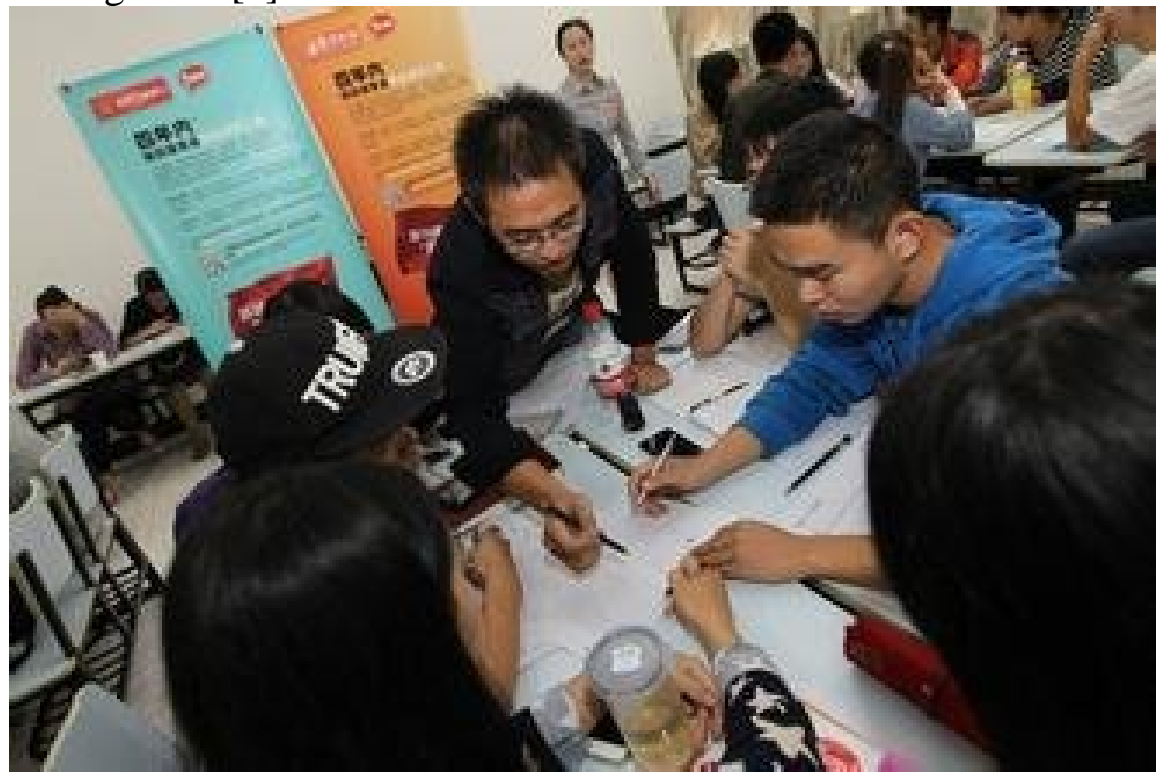

Figure 2

\subsubsection{Additional task}

In terms of mathematics, mathematical modeling is an important bridge for the effective communication with the real world, and it is the only way for mathematics to exert its application value. In recent years, mathematics modeling competition in higher mathematics is organized frequently in China, and it develops rapidly with the larger number of participant and the greater competition scale. Therefore, in actual teaching, teachers shall encourage students to learn in groups and to actively participate in mathematical modeling competition, shown in Figure 3. In competition, students can fully exert their individual intelligence without the guidance of teachers. And in teamwork, students can solve realistic problems with innovative thinking. In the whole process of competition, teachers just play a helping role in guiding students to scientifically analyze realistic problems, and explaining necessary conditions for the completion of competition by mathematics tool and knowledge contents. Whereas, students can practice themselves in competition, actively learn the field they know less, search relates literature on Internet, and complete the calculation with mathematics tool software. In the whole process, clear division of work and teamwork shall be ensured. In mathematical modeling, students can understand the essence of higher mathematics and realize the effective application of knowledge learned, and widen their learning thinking with the help of network literature, which has an important significance for the cultivation of students' scientific research ability. [9] 


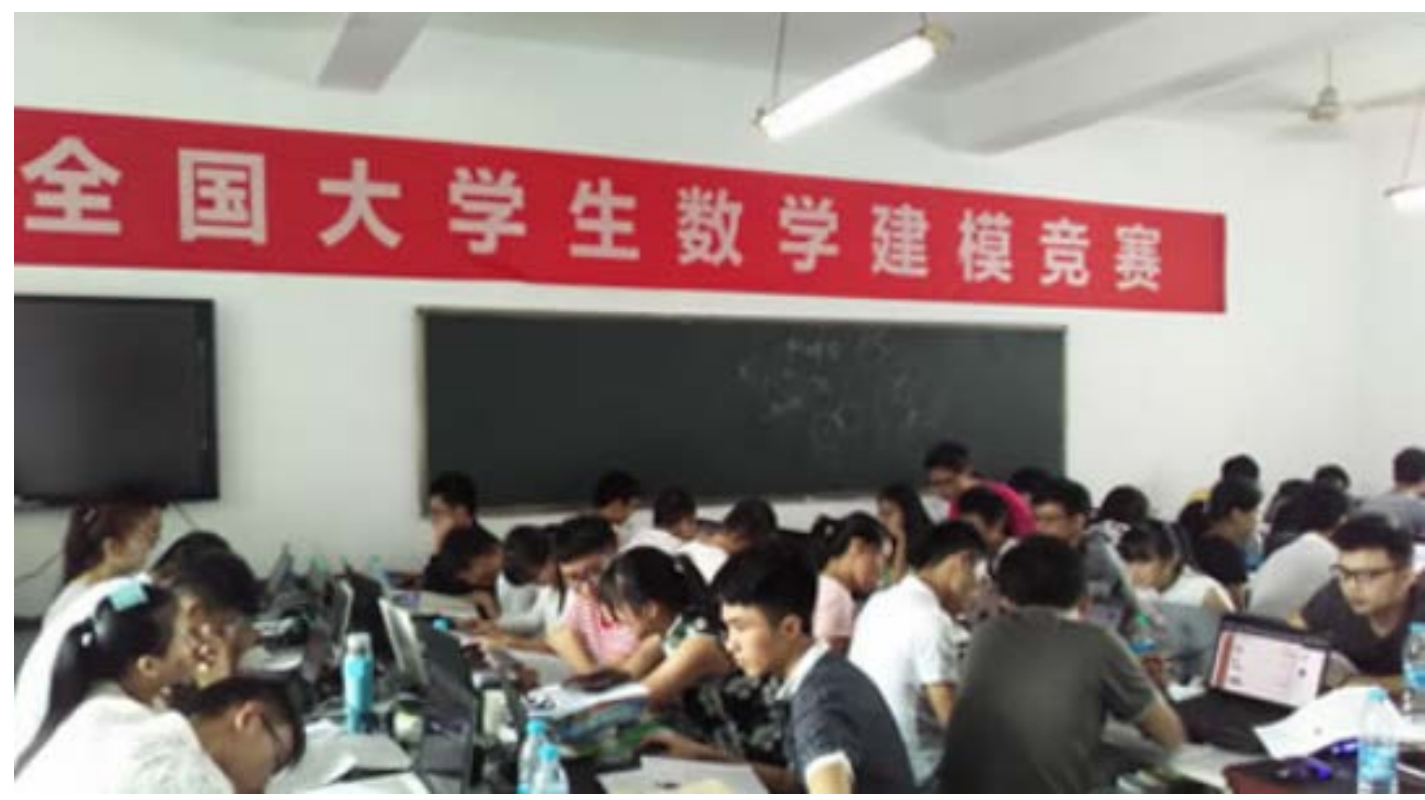

Figure 3

\subsection{The application in teaching experience}

It is necessary to do a good job in corresponding summary at the end of each teaching cycle, and timely correct the drawbacks. Firstly, the rationality of Internet resources selection and the effectiveness of resource utilization should be analyzed, to determine whether the resource base needs to be updated; secondly, it is necessary to summarize the task completion. For tasks with good completion status, it is necessary to confirm whether further deepening is needed. For tasks that are not ideal, the reasons for this situation should be analyzed to confirm whether it is because the difficulty of the task is set too high, or the knowledge in certain aspect needs to be strengthened, so as to determine whether the task mode should be changed; thirdly, it is necessary to pay attention to students, and strengthen the emphasis on teacher-student network communication records, summarize and feedback the information, summarize the common problems to be improved in the next teaching stage; fourthly, it is necessary to establish a database based on task evaluation and test scores, judge the role of task setting in higher mathematics classroom teaching, and analyze and master the weak links in the construction of students' knowledge system. On this basis, the higher mathematics classroom teaching with Internet as a tool and task-driven method as the foundation shall be continuously optimized. [10]

\section{Conclusion}

The popularized application of Internet information technology promotes the development of various fields. Especially, for higher mathematics classroom teaching, the application of Internet information technology can break the limit of times and space, so that students can study anywhere at any time, which plays an important role in improving the teaching quality and efficiency of higher mathematics. Therefore, in teaching, teachers in colleges and universities shall pay attention to Internet information technology, and conduct in-depth research, and fully apply it in teaching activities, so as to incessantly optimize the teaching of higher mathematics, enhance students' learning interest, at the same time, effectively improve students' comprehensive quality capacity and realize relative educational goal of colleges and universities.

\section{References}

[1] Li Yiming, Yang Yuemei. Research on the Application of Internet Information Technology in Higher Mathematics Classroom Teaching [J]. Finance Theory and Teaching, 2017,9(3):110-112.

[2] Sun Fuzhi. Research on the Application of Internet Information Technology in Higher 
Mathematics Classroom Teaching [J]. Knowledge Library, 2017,5(20).

[3] E Ning, Yang Yuemei. Research on the Implementation Strategy of In-depth Integration of Internet Information Technology and Higher Mathematics Classroom Teaching [J]. Finance Theory and Teaching, 2017,7(4):102-104.

[4] Tao Juchun, Wang Fen'e, Cao Wenquan. The Research about Optimization of Advanced Math's Instruction with Modern Information Technology [J]. Modern Educational Technology, 2013,4(6):67-70.

[5] Le Lihua, Yan Qisheng. Discussion on Higher Mathematics Teaching Assisted by Network Information Technology [J]. Education and Teaching Forum, 2018,6(38):266-268

[6] Cao Shuailei. Research and Practice of the “Teaching, Learning and Doing' Integration of Advanced Mathematics Based on the Information Technology Environment [J]. Higher Vocational Education-Journal of Tianjin Professional College, 2018,3(1):52-55.

[7] Shao Shili. Exploration of Integration Teaching of Information Technology and Higher Mathematics [J]. Shu Xue Da Shi Jie (Midmonth), 2018,9(7):12.

[8] Yang Qing. Research on the mixed teaching mode of "Higher Mathematics" based on information technology [J]. Jiangsu Science \& Technology Information, 2017,8(17):51-52.

[9] Dong Nianjiao. Paths to Integrate Higher Mathematics Teaching with Information Technology [J]. Technology Wind, 2018,6(13):49-50.

[10] Qi Chunling. The Application of Information Technology in Higher Mathematics Curriculum Teaching [J]. Western China Quality Education, 2018,4(5):116. 